\title{
perifèria
}

Número 15, diciembre 2011

www.periferia.name

\section{Mapa de redes personales. Una herramienta para el estudio de las remesas económicas y sociales con EgoNet}

\author{
Javier Ávila - Universidad Autónoma de Barcelona - Egolab-GRAFO ${ }^{1}$
}

\begin{abstract}
Resumen
El análisis integral de las remesas requiere repensar su unidad de análisis "clásica": el hogar. En sentido amplio, las remesas no circulan en el vacío social sino a través de las redes transnacionales del hogar transnacional del inmigrante, las cuales constituyen su micro-estructura. Con la globalización estas redes se vuelven más complejas y requieren de nuevas metodologías de análisis, que permitan identificar, analizar y representar esta complejidad. ¿Cómo estudiar las remesas en la nueva complejidad de las redes transnacionales? En este artículo proponemos utilizar el análisis de redes personales como herramienta para identificar las características de las redes de los inmigrantes emisores de remesas y construir las principales coordenadas de los mapas de sus comunidades personales, dentro de los cuales se desarrollan los microcircuitos de las redes de remesas.
\end{abstract}

Palabras clave: Redes personales, hogar transnacional, inmigrantes, remesas, Egonet.

\begin{abstract}
The integral analysis of remittances requires rethinking its unit of research: the home. In real sense, the remittances don't flow in a social empty, but its flow through the transnational networks of immigrants. Today, these transnational Networks are more complex. This new complexity of transnational networks requires a new perspective of analysis that includes also its social and cultural aspects. How does research this new complexity of the transnational networks and remittances? The theory of social networks offers a tool for reticular analysis, far away the traditional metaphor of network. So the social network analysis allows identify and analyses with precision the micro circuits of flowing of remittances between multi-nodal transnational spaces of sociability.
\end{abstract}

Key words: Social Network, transnational home, immigrants, remittances, Egonet.

\footnotetext{
1 Enviar correspondencia a: Javier Ávila Molero javila.molero@gmail.com o javilamolero@hotmail.com
} 


\section{perifèria}

Número 15, diciembre 2011

www.periferia.name

\section{Introducción}

Las remesas no circulan entre el vacío social, sino a través de las redes transnacionales que los inmigrantes conforman entre las sociedades de acogida y origen. Estas redes conforman micro-circuitos transnacionales que hacen posible el flujo de remesas.

De manera tradicional el estudio de las remesas se ha desarrollado desde un paradigma unidireccional, en sentido norte-sur, el cual consideraba como actores del proceso sólo a una persona emisora de remesas en la sociedad de acogida y a otra persona receptora de la remesa en la sociedad de origen; la cual se encargaba de redistribuir la remesa entre los miembros del hogar. Hoy en día este paradigma se ve desbordado por la creciente complejidad que vienen asumiendo las redes de los inmigrantes; en especial, las que conforman los hogares transnacionales. Producto de esta nueva complejidad se incrementan los nodos emisores y receptores de remesas al interior de los hogares transnacionales.

Las redes transnacionales constituyen las micro-estructuras por donde circulan las remesas. Su análisis nos permite visibilizar aspectos ocultos de sus microcircuitos y desarrollar gráficos sobre su complejidad. Esto nos permite identificar la complejidad de los micro-circuitos de emisión y recepción de las remesas entre el inmigrante (ego) y sus contactos (alteri).

Los sociogramas de redes personales son herramientas importantes para el estudio de las remesas. Sin embargo, con el auxilio de un software especializado en recoger y analizar datos de redes, se pueden hacer estudios de mayor complejidad. Egonet es un software de análisis de redes que permite realizar análisis profundos sobre las redes de remesas. La representación gráfica que Egonet hace de estos circuitos multi-nodales de emisión y recepción de las remesas es una herramienta importante para el desarrollo de entrevistas y etnografías sobre este tema, con mayor realismo y precisión.

El presente artículo analiza las redes de remesas. Lo hace desde una perspectiva antropológica, proponiendo representar la complejidad de los microcircuitos de las remesas con ayuda de la teoría de análisis de redes, y el uso del software Egonet. 


\section{perifèria}

Número 15, diciembre 2011

www.periferia.name

\section{Repensar las remesas}

Muchos autores han señalado la importancia de repensar las remesas más allá de sus evidentes sesgos económicos, incluyendo también los aspectos sociales y culturales involucrados en los procesos de transferencia de dinero, capital o bienes entre los inmigrantes y sus comunidades de origen (Levitt 1999; Goldring 2004; Sorensen 2004, 2005).

Esta perspectiva implica repensar el sentido y direccionalidad de las remesas, las cuales de manera tradicional han sido entendidas desde una perspectiva unidireccional, de sentido norte-sur, por otra más amplia, que también incluya los recursos económicos, sociales y culturales que las comunidades de origen envían a los inmigrantes, en sentido sur-norte, desde sus localidades y países de origen.

Ambos criterios, el de repensar los aspectos no-económicos de las remesas y considerar la bi-direccionalidad de sus flujos, implican redefinir la unidad de análisis "clásica" de las remesas: el hogar.

De manera tradicional, los estudios de remesas se han basado o bien en el análisis de los hogares emisores de remesas o bien en el de los hogares receptores en la sociedad de origen (Long 2008). Sin embargo, desde la teoría del transnacionalismo se observa que la separación entre hogares emisores y receptores es artificial; y que responde más a criterios geográficos propios del nacionalismo metodológico, que a criterios sociales. En ese sentido, a diferencia del concepto tradicional de hogar, anclado en criterios geográficos localistas propios del nacionalismo metodológico, los teóricos del transnacionalismo proponen el concepto de "hogar transnacional".

El hogar transnacional se puede considerar la unidad de análisis "mínima" para los estudios de remesas. A diferencia de los criterios geográficos, el hogar transnacional se considera a partir de los ámbitos de sociabilidad realmente existentes de cada miembro de un hogar; los cuales pueden ser "locales", pero también "no-locales"; articulados dentro de un mismo continuo reticular, que no 


\section{perifèria}

Número 15, diciembre 2011

www.periferia.name

necesariamente coincide con los entornos geográficos próximos, como bien señalan los estudios de redes personales elaborados por Ferrand (2002), Maya (2002), De Federico (2007) y Molina (2011).

En lo fundamental, el hogar transnacional es una "red", la cual incluye dentro de un mismo continuo al inmigrante emisor de remesas y sus familiares receptores en origen; pero también a los lazos fuertes que lo acompañan desde otros ámbitos cercanos. Estas redes constituyen un capital social importante, identificado por Peggy Levitt como uno de los elementos que conforman las remesas sociales (Levitt $1999)^{2}$.

¿Qué es el hogar transnacional? No es un simple agregado de parientes consanguíneos y afines que mantienen, a pesar de la distancia geográfica, una identidad familiar común. En lo fundamental, se trata de una "red" de vínculos activos entre los miembros del hogar que residen aquí y allá, entre los países de origen y destino, a través de la cual circulan remesas económicas y sociales, en un sentido bidireccional, de norte a sur y de sur a norte ${ }^{3}$.

\footnotetext{
${ }^{2}$ Las remesas sociales están conformadas por: a) estructuras normativas, b) sistemas de prácticas y c) capital social. Las estructuras normativas son definidas como ideas, valores y creencias; normas de relacionamiento; nociones sobre responsabilidad familiar; estándares de género, clase y étnica; participación sociopolítica y expectativas sobre el desempeño de las instituciones. Incluyen además percepciones y valores aprendidos por el migrante y sobre los costos y beneficios de la migración.
}

Los sistemas de práctica tienen que ver con las acciones formadas a partir de las estructuras normativas: labores del hogar, prácticas religiosas, liderazgo y participación sociopolítica. Incluyen el acceso, reivindicación de la justicia y ejercicio de derechos. Asimismo, acciones basadas en los criterios del migrante sobre cómo desarrollar proyectos, creación de cooperativas e inversiones. Reconfiguración en las relaciones familiares, de género y etnia. Contiene cambios en el acceso a programas de salud, educación universitaria o técnica, conocimientos adquiridos y practicados luego del retorno del migrante a su comunidad de origen.

El capital social se concentra en lazos de solidaridad que el migrante recibe a través de redes sociales.

Respecto a los mecanismos de transferencia de las remesas sociales, se encuentran en el intercambio de cartas, videos, cassettes, fotografías y llamadas telefónicas (Levitt 1999). A estos se pueden agregar otros más frecuentes como el correo electrónico y video conferencias a través de Internet.

${ }^{3}$ Queda claro que las remesas económicas no circulan de manera azarosa, sino a través de las redes de los hogares transnacionales. No obstante, es poco lo conocemos sobre la naturaleza de estas redes. 


\section{perifèria}

Número 15, diciembre 2011

www.periferia.name

\section{El nivel meso de las redes}

Las personas desarrollamos nuestra vida cotidiana dentro de un conjunto de relaciones sociales que, en su conjunto, llamamos "sociedad". Desde las ciencias sociales se han desarrollado varias formas de analizar estas relaciones. A grandes rasgos, se pueden identificar dos grandes perspectivas. Una primera, "macro", que pone énfasis en el estudio de grandes estructuras y una segunda, "micro", que pone énfasis en el estudio del individuo y su acción social.

Los puntos de partida de estas dos grandes perspectivas son diferentes. Sin embargo, sus caminos no son necesariamente antagónicos y equidistantes. En términos generales, la perspectiva macro explicaría el comportamiento social desde el análisis de las grandes estructuras, mientras que la perspectiva micro lo haría desde la acción social de los individuos.

Sin embargo, se puede identificar un nivel intermedio entre lo macro y micro: el nivel meso. Se trataría de un nivel donde individuos y estructuras se encuentran profundamente interrelacionados; donde la dicotomía absoluta entre "individuo" y "sociedad" pierde rigidez. En este nivel meso, la relación entre "sujeto" y "estructura" sería un campo continuo, donde lo macro se expresa en lo micro y viceversa. Este sería el nivel del análisis de redes sociales, como eslabones entre los otros niveles, como se puede apreciar en la figura $1^{4}$.

\footnotetext{
${ }^{4}$ De esta manera, el análisis de redes sociales permite comprender cuál es la estructura y la composición de las relaciones entre personas, los "constreñimientos" que estas estructuras imponen a los actores, pero también cuáles son las "oportunidades" para el desarrollo de la acción social. Este énfasis en la "estructura" y "acción" permite comprender, de manera simultánea, a "la-sociedad-en-el-individuo" y al "individuo-en-la-sociedad".
} 


\section{perifèria}

Número 15, diciembre 2011

www.periferia.name

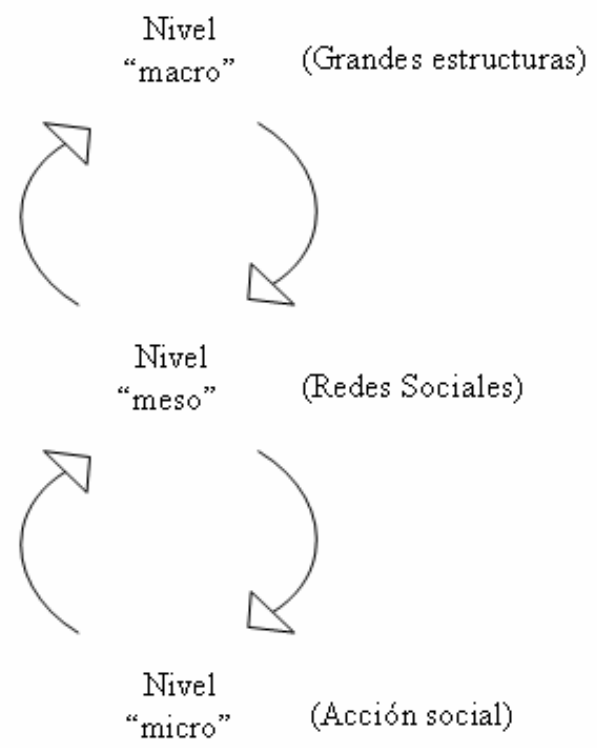

Figura 1.

Desde esta perspectiva, el análisis de redes sociales ofrece modelos de interpretación de las interacciones sociales. Existe la posibilidad de hacer un análisis que ponga énfasis en el estudio del sujeto y sus prácticas de sociabilidad en varios espacios. En este caso, el análisis de redes puede asumir como ámbito de estudio las redes personales que el sujeto desarrolla con sus alteri en varios espacios de sociabilidad. El análisis de la estructura y composición de las redes personales ofrece una radiografía muy precisa de la vida social del sujeto.

\section{Redes y sociabilidad}

Las prácticas de sociabilidad se constituyen a través de los vínculos que desarrollan dos o más personas. No se trata de cualquier tipo de vínculo. Estos tienen que desarrollar un carácter reciproco y asumir cierto nivel de institucionalización en el tiempo. Las prácticas de sociabilidad pueden ser formales o informales y se pueden 


\section{perifèria}

Número 15, diciembre 2011

www.periferia.name

desarrollar tanto en la esfera privada como pública. Sus ámbitos de desarrollo se suelen denominar "espacios de sociabilidad" y constituyen los "micro escenarios" donde cada sujeto va desarrollando, de manera concreta, sus procesos de socialización (en plural) en una sociedad y cultura.

Desde esta perspectiva, las redes personales se construye sobre la base de las interacciones que el sujeto desarrolla en esos espacios. La comprensión de las prácticas sociales y representaciones culturales, desde las cuales el sujeto elabora su comunidad, sería una estrategia de análisis integral de los procesos de sociabilidad del sujeto, los cuales en un mundo globalizado se desarrollan en ámbitos tanto "locales" como "no-locales".

Para comprender las redes y ámbitos de sociabilidad es necesario también analizar las expresiones simbólicas que las personas desarrollan en este proceso. Es importante tomar en cuenta que los procesos de constitución de redes sociales tienen tanto una expresión relacional práctica como otra simbólica. A través de la acción social el sujeto se puede socializar en una cultura, y a través de esa cultura el sujeto puede desarrollar su acción social ${ }^{5}$.

¿Cómo entender las dimensiones sociales y culturales de las remesas desde la multiplicidad e interconexión entre escenarios "aquí y allá" y desde el punto de vista de los propios actores? Sin duda alguna, para ello es necesario familiarizarse con las prácticas, narrativas y esquemas de pensamiento que manifiestan las personas con respecto a la movilidad geográfica y social; pero desde el punto de vista de los problemas relacionados con la reproducción de las estrategias del modo de vida y las identidades sociales o nociones de "sentido de pertenencia", en el

\footnotetext{
${ }^{5}$ Desde la perspectiva antropológica, la constitución de estas redes requiere de un proceso paralelo de aprendizaje de códigos culturales, que hagan posible la interacción entre dos personas. Para esto, es necesario el desarrollo de un umbral comunicativo "mínimo" que permita el intercambio de símbolos entre sujetos. Estos símbolos están constituidos por información, valores e identidades que, en conjunto, constituyen una "cultura de sociabilidad", desde la cual es posible que el sujeto desarrolle sus redes sociales. De esta manera, las redes no se desarrollan al margen de las representaciones simbólicas de los sujetos, sino en correspondencia con éstas. De esta manera, para hablar de sociabilidad y comunidades personales, es necesario referirse no sólo a su condición práctica sino también a sus representaciones simbólicas. Los sujetos desarrollan sus comunidades personales a través de prácticas sociales, y estas se desarrollan teniendo en mente algún modelo implícito o explícito de comunidad.
} 


\section{perifèria}

Número 15, diciembre 2011

www.periferia.name

contexto de las circunstancias de la vida cotidiana en medio de las cuales se presentan.

Para esto es necesario comprender a nivel micro y etnográfico los entornos de sociabilidad de los miembros de cada hogar transnacional, pero no sólo desde el discurso y la narrativa, sino también desde sus prácticas e interacciones sociales. Es decir, desde las redes sociales que, a nivel personal, establecen tanto "aquí y allá"6. Para ello, los sociodramas constituyen herramientas de análisis e interpretación importantes.

\section{Dibujando redes: los sociogramas}

Los sociogramas son representaciones gráficas que los antropólogos hacen de las redes sociales. Los usos del sociodrama se remotan al año 1957, cuando Epstein representó gráficamente la red de habladurías en torno a una pareja de esposos nativos africanos, combinando grafos de la teoría de parentesco con representaciones de las características de los vínculos entre ego y sus alteri, así como sobre la composición de los alteri.

La propuesta de Epstein incluía una diferenciación entre círculos de sociabilidad concéntricos, en donde el primero representaba las interacciones directas entre el matrimonio "ego" y sus alteri con quienes tenían vínculos directos, mientras que el segundo ubicada a las personas con quienes el matrimonio "ego" no tenía interacción directa, pero recibían los chismes, como se puede apreciar en la figura 2.

\footnotetext{
${ }^{6}$ A primera vista, las redes aparecen como un complejo difícil de desentrañar. Sin embargo, detrás de esa maraña existen patrones de interacción, que influyen en el comportamiento de las personas implicadas, aunque no sean conscientes de esta influencia. Desde este enfoque, la sociedad no la conforman los individuos, sino el agregado de individuos y patrones de relaciones, simultáneamente.
} 


\section{perifèria}

Número 15, diciembre 2011

www.periferia.name

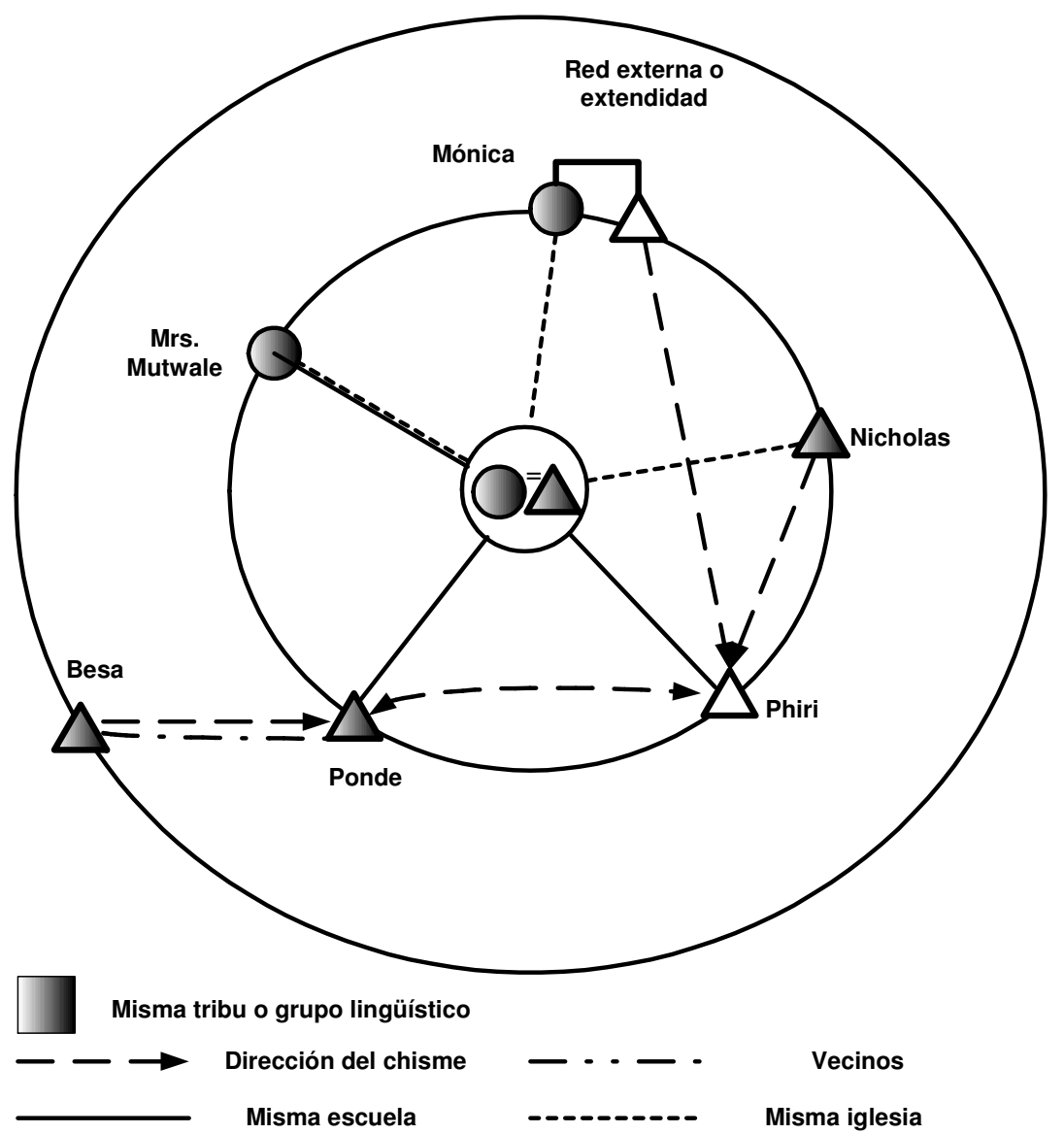

Figura 2. Sociograma de red de habladurías de Epstein (1957)

Cuatro décadas después el sociólogo Barry Wellman retomó el uso de sociogramas para el análisis de redes personales; esta vez incluyendo algunas modificaciones en los grafos de representación. En la propuesta de Wellman el primer círculo del sociograma representaba los lazos fuertes de ego y el segundo círculo sus lazos débiles. Los diferentes tipos de relaciones ya no se representaban con diferentes líneas, sino a través de cuadrantes, los cuales podían ser de familia, trabajo, vecindad o amistad. Dentro de cada cuadrante se ubicaban los alteri según correspondía, como se puede apreciar en la figura 3. 


\section{perifèria}

Número 15, diciembre 2011

www.periferia.name

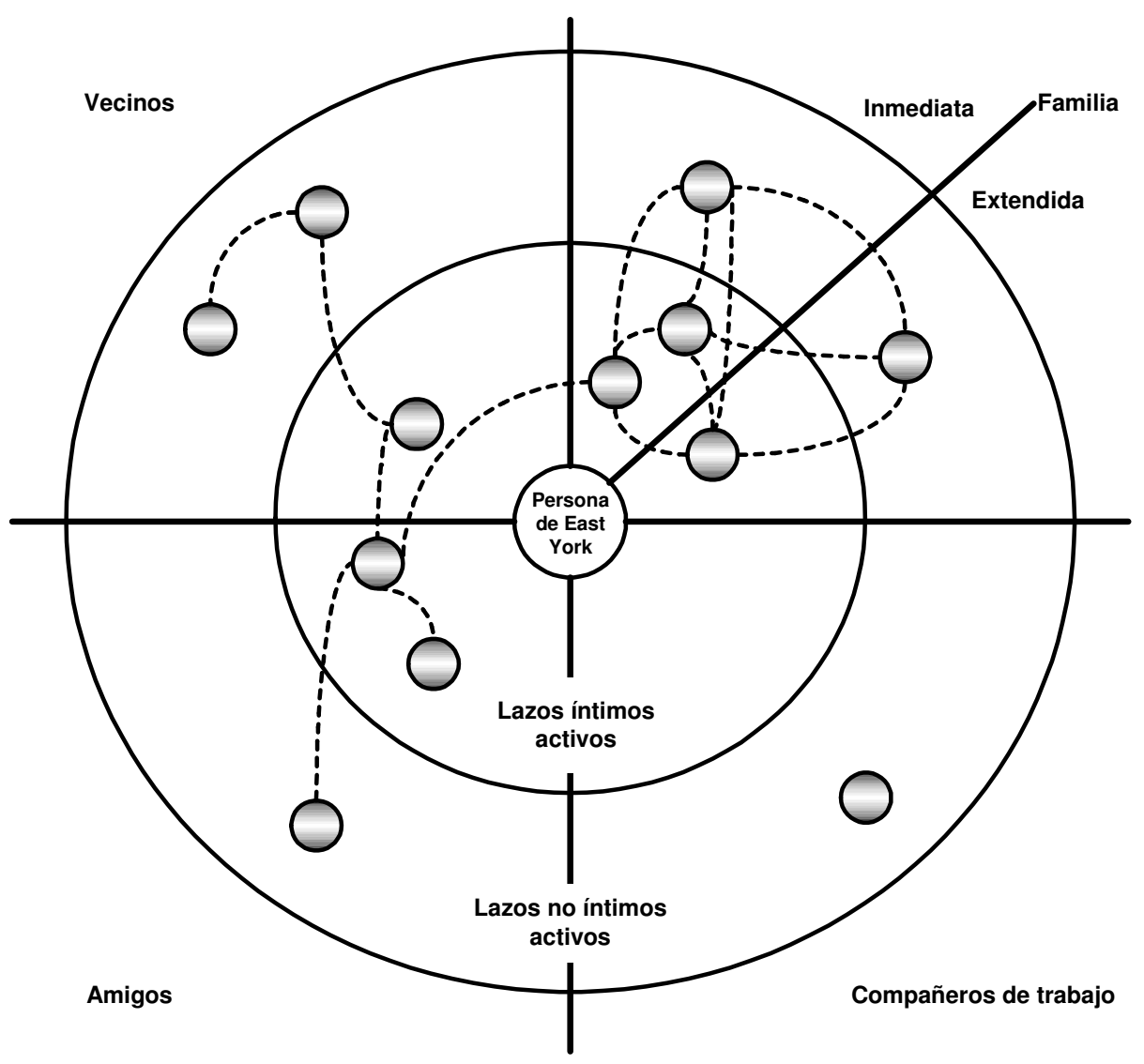

Figura 3. Sociograma red personal East York, Wellman (1999)

Sin duda, las propuestas de Epstein y Wellman constituyen aportes de consideración para comprender mejor la complejidad de los vínculos de las personas. No obstante, al realizarse de manera artesanal, con lápiz y papel, presentan limitaciones para ir más allá de un número reducido de alteri.

\section{Análisis de redes personales con Egonet}

En su sentido original, el estudio de las redes personales se enfocaba en el análisis de los "lazos fuertes" (Wellman 1988), los cuales solían estar compuestos, en 


\section{perifèria}

Número 15, diciembre 2011

www.periferia.name

promedio, por una docena de "alteri" o contactos. Sin embargo, de manera reciente, Chris McCarty (2002) y José Luis Molina (2007) han recomendado extender el foco del análisis de las redes personales hacia el conjunto de su comunidad personal. Para esto, se requiere ampliar el número de "alteri" 0 "contactos" al menos a 45 personas.

Este incremento en la cantidad de alteri ofrecería una muestra más confiable sobre el conjunto de las redes personales de un individuo y permite que el análisis se amplíe desde el núcleo restringido de "lazos fuertes" hacia la periferia más extensa de sus "lazos débiles". Este giro metodológico es importante porque no sólo permite profundizar el análisis de las variables de composición de las comunidades personales, sino también incluir en el estudio de las redes personales variables de "estructura", como si se tratara de redes completas o sociocéntricas (Molina 2007).

Sin embargo, el estudio de las comunidades personales con una muestra de 45 alteri es complejo. Para ello se requiere del auxilio de software especializado en recolección, análisis y visualización de datos reticulares, como es el caso del software Egonet. Este software está especialmente diseñado para la recolección y análisis de datos sobre redes personales. Egonet permite crear encuestas, recoger datos y analizarlos con medidas de la teoría del análisis de redes. También ofrece representaciones gráficas de los sociogramas de las redes personales analizadas.

El siguiente gráfico representa el esquema de una red personal compleja y la identificación de las principales variables de composición y estructura. Las variables de composición de la red personal se refieren a las características de los alteri (edad, sexo, nacionalidad, ocupación, etc.), y las variables de estructura a las características de los vínculos entre los alteri de la red personal de ego (densidad, cluster, betweenness, etc.), como se puede apreciar en la figura 4. 


\section{perifèria}

Número 15, diciembre 2011

www.periferia.name

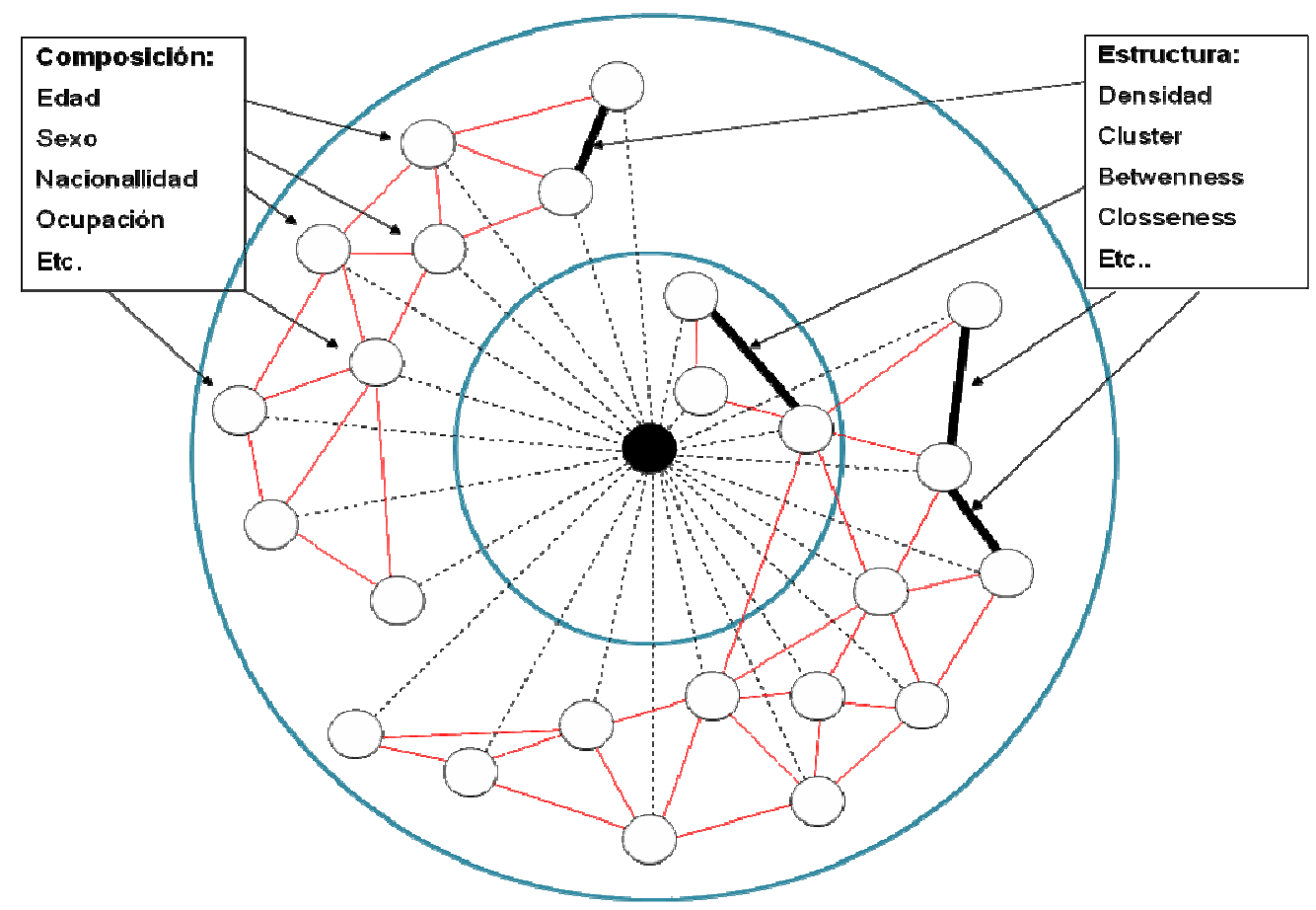

Figura 4. Esquema de una red personal compleja y variables de estructura y composición

Egonet representa los sociogramas sin incluir a ego y sus vínculos con los demás alteri. Como ego tiene vínculos con cada uno de los alteri, por economía visual los gráficos de las redes personales solo representan a los alteri de ego y sus vínculos, para facilitar la lectura del sociodrama, tal como vamos a observar a continuación.

\section{Las redes personales de una emisora de remesas: Corina}

Corina es una joven peruana de 26 años que emigró hacia Madrid-España el año 2005. Consiguió permiso de trabajo y su ingreso fue legal. En la actualidad ella trabaja en el Corte Inglés (centro comercial). Sus planes son trabajar por un tiempo y luego regresar para Perú. Corina es emisora regular de remesas hacia Lima, las cuales recibe su madre; sin embargo, envía y recibe remesas de otras personas, como veremos más adelante. Las remesas que Corina envía a su madre se destinan fundamentalmente para la construcción de la segunda y tercera planta 


\section{revista de recerca i formació en antropologia}

\section{perifèria}

Número 15, diciembre 2011

www.periferia.name

de su casa, la cual planea usar como apartamentos para alquiler y/o venta. En cinco años más Corina planea regresar a Perú, cuando su proyecto esté concluido.

Entrevistamos a Corina y le aplicamos una encuesta de redes personales con Egonet. Esta encuesta nos permitió recoger importante información sobre la red personal de Corina y sus variables de estructura y composición. Los siguientes gráficos nos muestran los sociogramas que Egonet permite elaborar, inclusive combinando diferentes variables.

La figura 05 nos muestra la ubicación geográfica de los alteri de la red personal de Corina. En este caso, los nodos rojos representan los alteris que residen en Perú; los negros los que residen en España; y los blancos los que residen en otros países, como se puede apreciar en la figura 5.

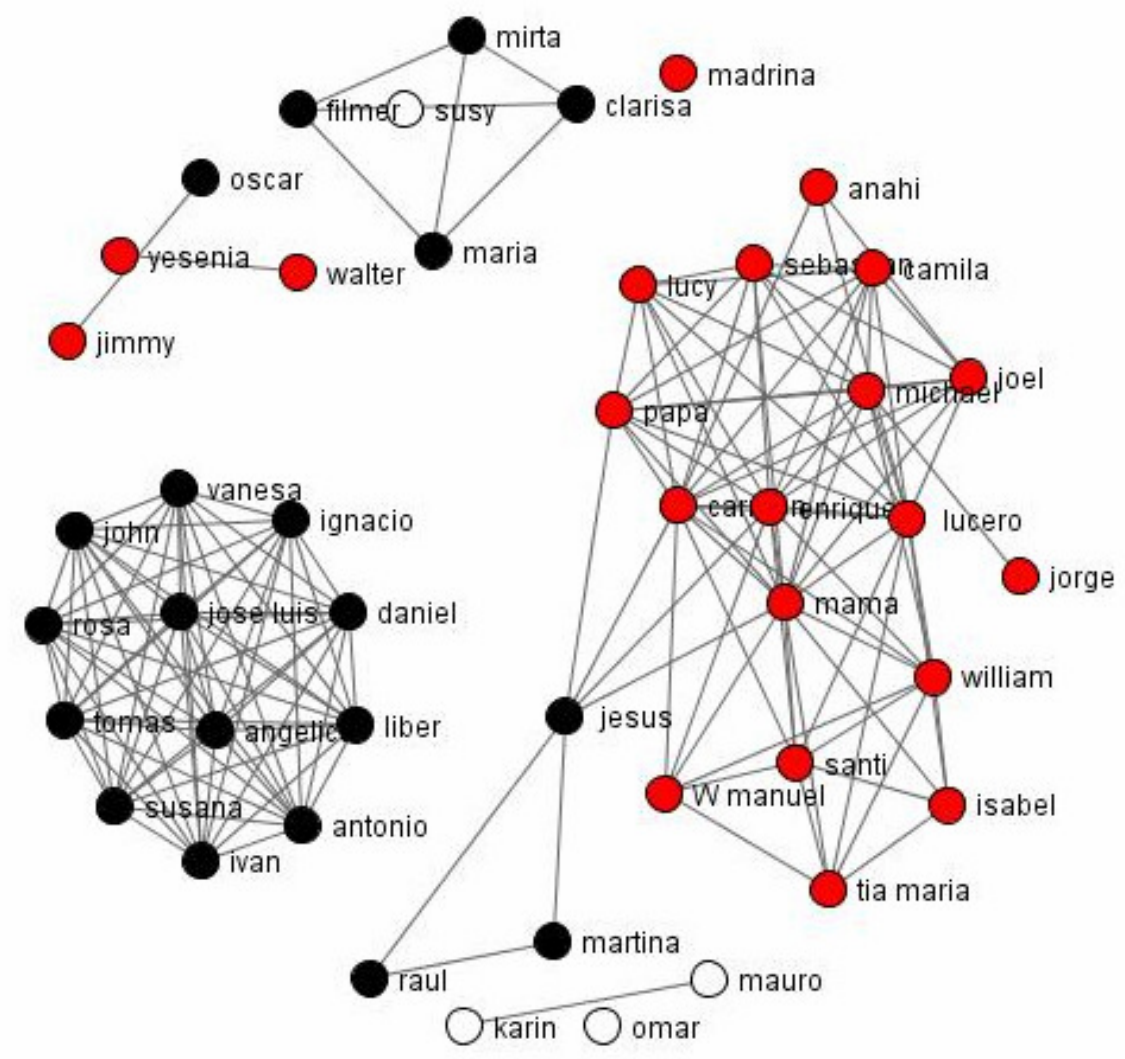

Figura 5. Red personal de mujer inmigrante peruana en España 


\section{perifèria}

Número 15, diciembre 2011

www.periferia.name

En este caso, se puede apreciar con nitidez que se trata de una red transnacional, con sus alteri distribuidos entre España y Perú, incluyendo también algunos alteri residentes en otros países.

La figura 6 nos muestra la procedencia nacional de los alteri que conforman la red personal de Corina. En este caso, se puede combinar la información de esta nueva variable con la de la variable anterior. El origen nacional de los alteri se representa utilizando las formas de los nodos. Los nodos de circulares representan los alteri de origen peruano; los cuadrados a los alteri de origen español; y los triangulares a los de otros países de procedencia, como se puede apreciar en la figura 6 .

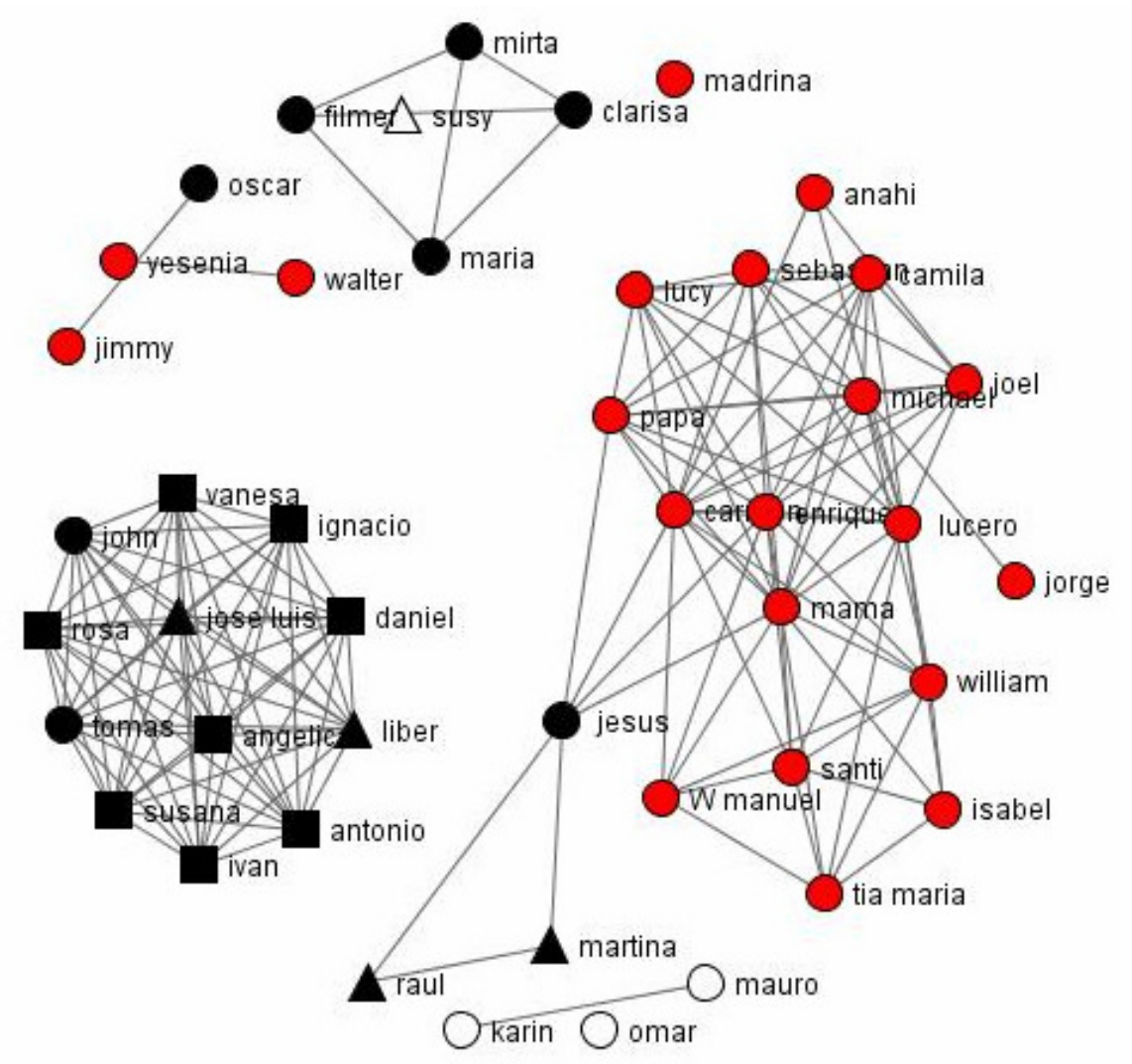

Figura 6. Red personal de mujer inmigrante peruana en España 


\section{perifèria}

Número 15, diciembre 2011

www.periferia.name

Se puede apreciar que se trata de una red interétnica, que en su ámbito en España incluye personas de diferentes procedencias nacionales.

Finalmente, la figura 7 nos muestra las redes de remesas. En este caso, los nodos de la red de Corina con quienes ella mantiene un frecuente flujo de emisión y/o recepción de remesas. En este caso, estos nodos se representan con un mayor tamaño.

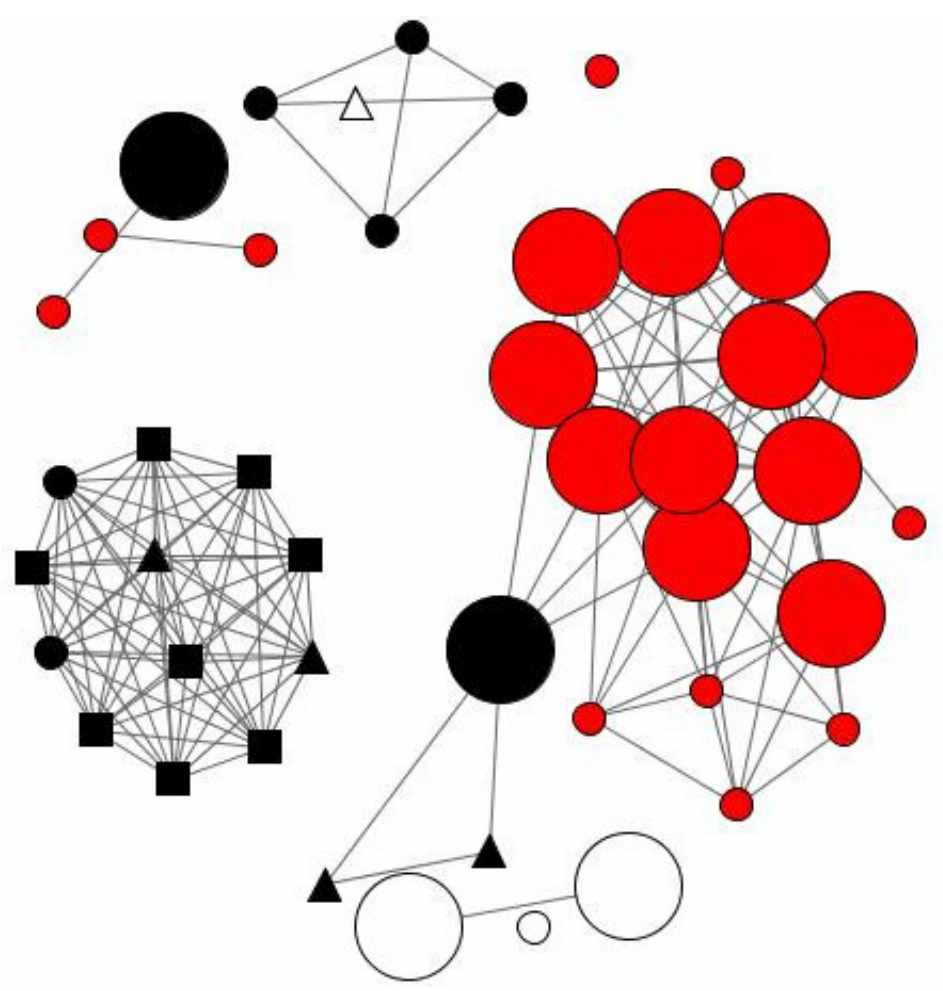

Figura 7. Red personal de mujer inmigrante peruana en España

Como se puede apreciar, se trata de una microrred de remesas compleja, que involucra un número amplio de nodos. Este gráfico nos muestra que los 


\section{perifèria}

Número 15, diciembre 2011

www.periferia.name

intercambios son mayores a la imagen clásica entre un inmigrante emisor y otro receptor.

\section{Mapa de las redes de Corina}

Los sociogramas desarrollados con Egonet constituyen datos importantes para desarrollar un mapa de redes personales, el cual nos podría permitir representar con mayor claridad y precisión la composición transnacional de una red personal y los diferentes tipos de relaciones a su interior, junto con la microrred de remesas que se desarrolla.

El mapa ha sido organizado en cuadrantes y círculos concéntricos, de manera similar a las propuestas pioneras de Epstein y Wellman. Sin embargo, en este caso, al tratarse de redes personales de mayor complejidad cuantitativa y cualitativa se ha variado los sentidos de presentación original. En este caso, los círculos representan los países de residencia de los alteri, siendo el primer círculo de color negro España y el segundo circulo de color rojo Perú. Los nodos ubicados fuera de ambos círculos (color blanco) representan miembros de su red que residen en otros países que no son ni España ni Perú. Por su parte, los cuadrantes representan el tipo de relación que los alteri mantienen con ego, los cuales pueden ser vínculos de familia, vecindad, trabajo o amistad. En este caso hemos representado con diferentes formas el tipo de relación que los alteri mantienen con Corina, siendo los triangulos compañeros de trabajo; los círculos familiares; y los cuadrados familiares, como se puede apreciar en la figura 8. 


\section{perifèria}

Número 15, diciembre 2011

www.periferia.name

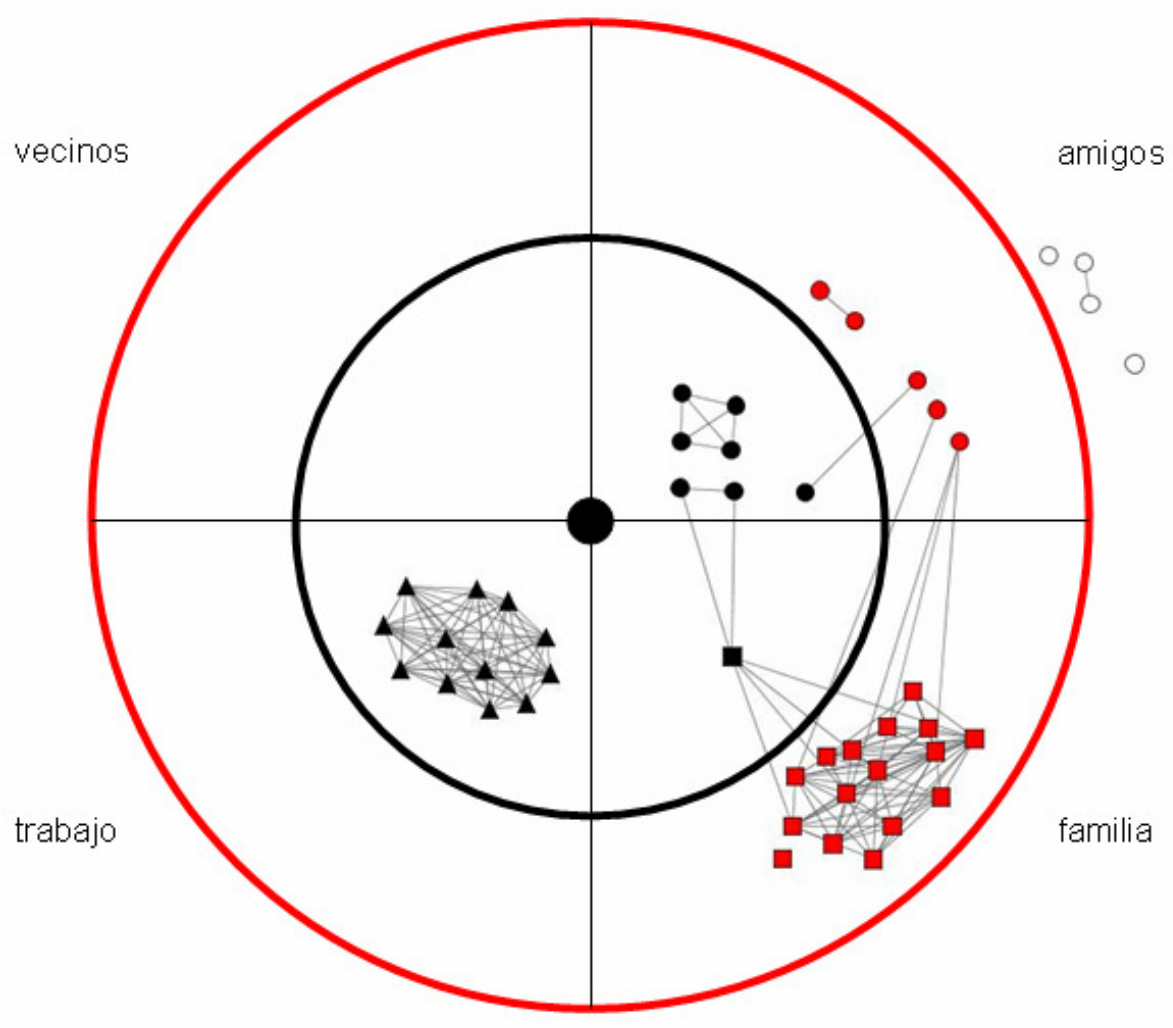

Figura 8. Red personal de inmigrante peruana en España

Este mapa de redes personales nos permite identificar con mayor precisión la composición geográfica y social de la red personal de la mujer peruana, tanto en sus dimensiones "locales" y "no-locales". También identificar rápidamente algunas características estructurales de la red, como los cluster que la conforman y los nodos con mayor betweenness a su interior. Junto a ello, el mapa nos permite también identificar a los miembros de la red personal que conforman el "hogar transnacional", los que estarían en el cuadrante "familia". Sin embargo, en este caso, la identificación de los miembros que conforman el hogar transnacional no se haría desde una perspectiva nominal, sino desde una perspectiva práctica, en función a los vínculos realmente existentes de sociabilidad familiar desarrollados. Este mapa del hogar transnacional es particularmente útil para iniciar el análisis de las "redes de remesas". 


\section{perifèria}

Número 15, diciembre 2011

www.periferia.name

Ahora bien, el mapa no se limita a identificar a los miembros del hogar transnacional. Nos permite identificar también a miembros activos de la red personal del inmigrante en los otros cuadrantes, como el laboral, vecinal o el más genérico de amistad? .

Siguiendo con la red de Corina, los siguientes gráficos representan las redes de envío y recepción de remesas al interior de su red personal. En este caso, los nodos emisores y receptores de las remesas han sido coloreados de negro, para facilitar su identificación; además se incluyen flechas que representan la dirección de los flujos de envío y recepción de remesas, como se puede apreciar en las figuras 9 y 10.

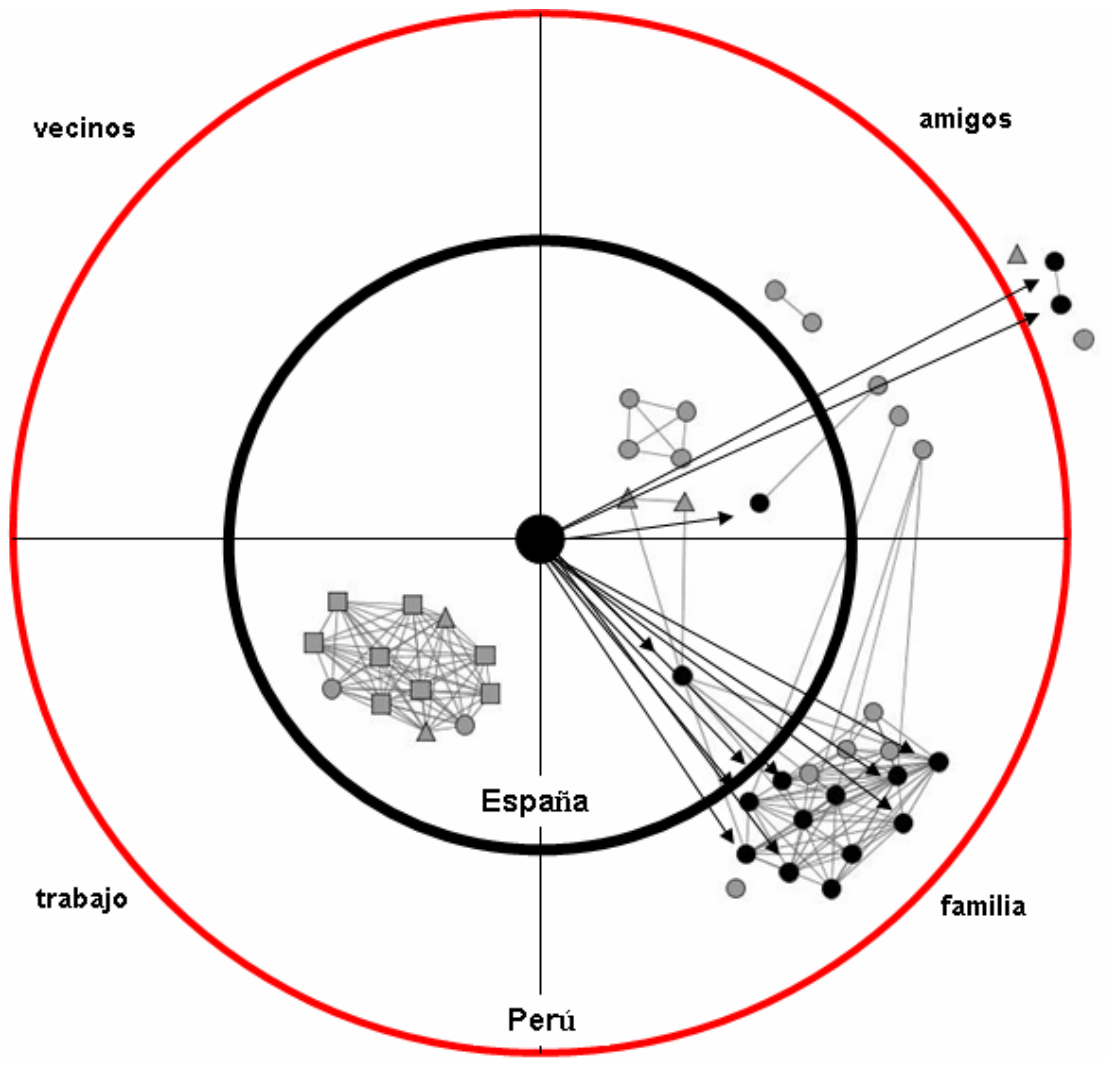

Figura 9. Envío de remesas por parte de Corina hacia sus alteri

\footnotetext{
7 El mapa facilita el análisis de las redes de remesas y visibiliza los microcircuitos a través de los cuales circulan no sólo los capitales económicos, sino también los sociales y culturales intercambiados entre los miembros de la red.
} 


\section{perifèria}

Número 15, diciembre 2011

www.periferia.name

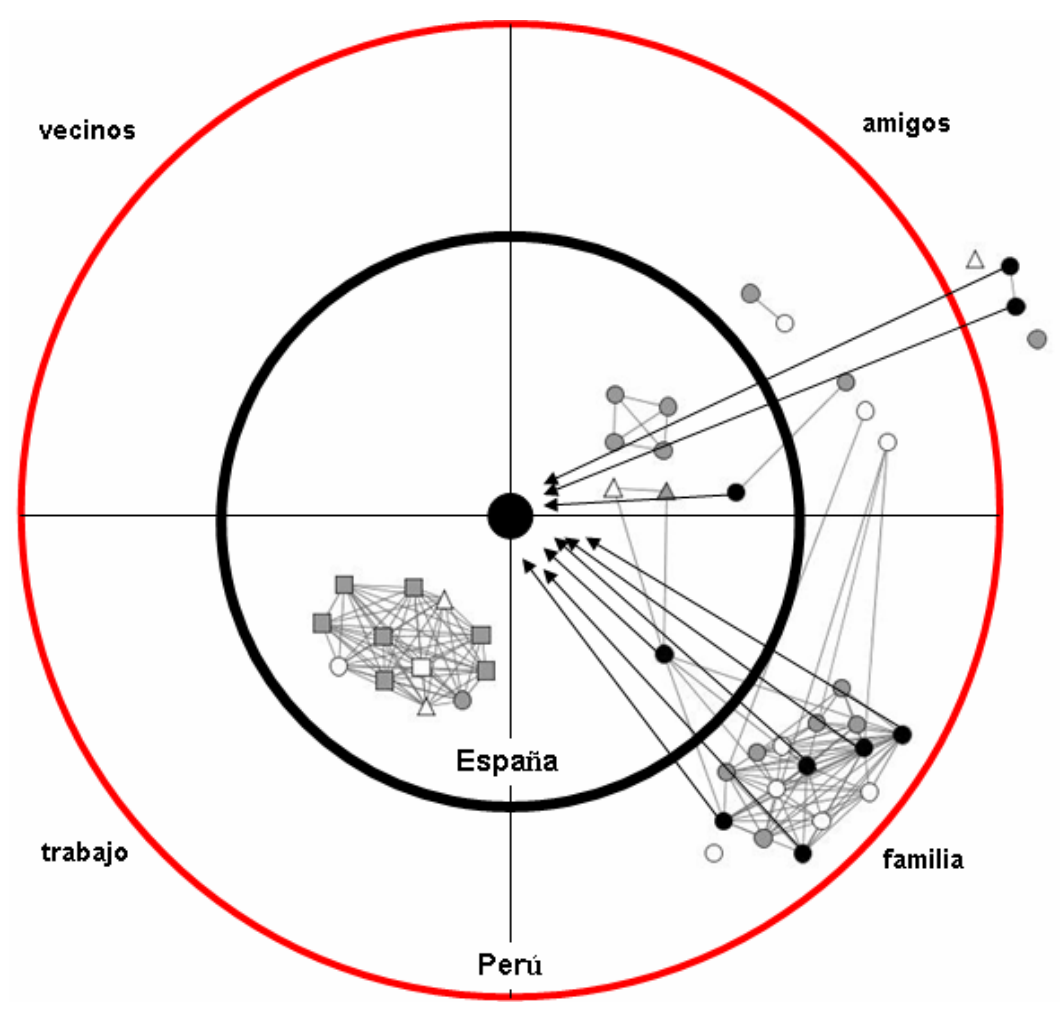

Figura 10. Recepción de remesas por parte de Corina

En ambos gráficos se puede apreciar que los circuitos de emisión de remesas no sólo se desarrollan entre un emisor en España y un receptor en Perú, sino que incluyen a un número mayor de nodos que no sólo se ubican dentro del hogar transnacional -familia- en Perú, sino también incluye nodos del cuadrante "amistad" residentes en Perú, e inclusive en otros países fuera del circuito EspañaPerú, ofreciendo una imagen más realista de la complejidad de las redes de remesas contemporáneas, que no sólo son unidireccionales en sentido norte-sur, sino también bidireccionales en sentido sur-norte. 


\section{perifèria}

Número 15, diciembre 2011

www.periferia.name

\section{Conclusiones}

Las redes personales de los inmigrantes vienen asumiendo una nueva complejidad, que se expresa en el desarrollo de redes transnacionales multinodales activas en espacios geográficos dispersos. Estas redes transnacionales constituyen las microestructuras por las que circulan las remesas económicas.

Los sociogramas de análisis de redes personales constituyen herramientas útiles para visibilizar la complejidad de estas redes. Egonet permite recoger, analizar y visualizar redes personales complejas, a través de las cuales se pueden identificar las microestructuras de circulación de las remesas.

Con los sociogramas elaborados por Egonet es posible desarrollar mapas de redes personales, ubicando en un mismo gráfico ordenador variables de estructura y composición de la red. En el caso analizado, se identificaron la ubicación de los nodos, el tipo de relación con ego, y su participación en el envío y recepción de remesas.

Los resultados del análisis nos han mostrado que es posible identificar los microcircuitos de las remesas, en los cuales se puede apreciar que los flujos de remesas no sólo se desarrollan entre un emisor en España y un receptor en Perú, sino que incluyen a un número mayor de nodos emisores y receptores. Estos nodos no sólo se ubican dentro del ámbito del hogar transnacional -la familia- en España y Perú, sino también en el cuadrante "amistad". Más aún, estos nodos no residen únicamente en Perú, sino inclusive en otros países fuera del circuito transnacional establecido entre España-Perú.

Este análisis ofrece una perspectiva más realista acerca de la nueva complejidad de las redes de remesas contemporáneas, las cuales no circulan de manera unidireccional en sentido norte-sur, desde España hacia Perú, sino de manera bidireccionales, también en sentido sur-norte.

Finalmente, el mapa de redes al identificar los microcircuitos de remesas, se constituye en una herramienta hermenéutica importante para el desarrollo de entrevistas sobre las remesas sociales, ya que hace visible sus circuitos de flujo. 


\section{perifèria}

Número 15, diciembre 2011

www.periferia.name

\section{Bibliografía}

De Federico, Ainoa (2004). "Los espacios sociales de la transnacionalidad. Una tipología de la integración relacional de los migrantes". Revista Redes, Vol. 7, Octubre - Noviembre. http://revistaredes.rediris.es

Ferrand, Alexis (2002). "Las comunidades locales como estructuras meso". Revista Redes, Vol. 3 \#4, Septiembre-Noviembre. http://revistaredes.rediris.es

Goldring, Luin (2004). "Family and Collective Remittances to Mexico: a Multidimensional Typology". Development and Change 35(4): 799-840, USA.

Levitt, Peggy (1999). "Social remittances: migration driven local-level forms of cultural diffusion". International migratino reviwer, vol. 32, núm 4. pp. 926-948.

Long, Norman (2008). "Modos de vida transnacionales, prácticas organizativas y remesas sociales en el centro de Perú". Revista Colombiana de Antropología, Volumen 44 (2), julio-diciembre 2008, pp. 337-372.

Maya Jariego, Isidro (2002). "Tipos de redes personales de los inmigrantes y adaptación psicológica". Revista Redes, Vol.1,\#4, enero. http://revistaredes.rediris.es

Mccarty, Chris (2002). Structure in Personal Networks. Journal of Social Structure $3(1)$.

Molina, José Luis (2007). "El estudio de las redes personales: contribuciones, métodos y perspectivas". Empiria 10: 71-106.

(2011) "La dispersión geográfica de las redes personales: cálculo y significado". REDES- Revista hispana para el análisis de redes sociales, Vol.20,\#5, Universidad Autónoma de Barcelona.

Sørensen, N.N. (2004). "Migrant Transfers as a Development Tool". DIIS Working Paper 16, http://www.diis.dk/graphics/Publications/WP2004/nns_development_dimension.pdf (2005). "Globalización, Género y Migración Transnacional". En A. Escrivá \& N. Ribas (eds.) Migración y Desarrollo. Córdoba: Publicaciones del Consejo Superior 


\section{perifèria}

Número 15, diciembre 2011

www.periferia.name

de Investigaciones Científicas.

Wellman, Barry, Peter J. Carrington \& Alan Hall (1988). "Networks as personal communities". En Wellman, Barry \& Stephen D. Berkowitz (eds.). Social Structures; A Network Approach. Cambridge: Cambridge University Press. 